\title{
Síndrome congênita do vírus Zika: perfil sociodemográfico das mães
}

\author{
Paula de Souza Silva Freitas, ${ }^{1}$ Gabriella Barreto Soares, ${ }^{1}$ Helaine Jacinta Salvador Mocelin, ${ }^{1}$ \\ Larissa Carolina Xavier Lacerda, ${ }^{2}$ Thiago Nascimento do Prado, ${ }^{1}$ Carolina Maia Martins Sales, ${ }^{3}$ \\ Freddy Perez, ${ }^{4}$ Elda Coelho de Azevedo Bussinger ${ }^{5}$ e Ethel Leonor Noia Maciel ${ }^{1}$
}

Como citar

Freitas PSS, Soares GB, Mocelin HJS, Lacerda LCX, Prado TN, Sales CMM, et al. Síndrome congênita do vírus Zika: perfil sociodemográfico das mães. Rev Panam Salud Publica. 2019;43:e24. https://doi.org/10.26633/RPSP.2019.24

RESUMO

Objetivo. Descrever o perfil sociodemográfico de mães de crianças com síndrome congênita do Zika. Métodos. Trata-se de um estudo descritivo, transversal, de abordagem quantitativa. Foram convidadas a participar todas as 39 mães de bebês nascidos vivos entre os casos notificados em 2015 e 2016 com diagnóstico confirmado de síndrome congênita do Zika no Estado da Saúde do Espírito Santo. Dessas 39 mulheres, 25 concordaram em participar. Para a coleta de dados foram utilizados um formulário para identificar o perfil sociodemográfico e um diário de campo.

Resultados. Das 25 mães, 19 (74,0\%) se declararam não brancas e 16 declararam (64,0\%) possuir companheiro. Quanto à escolaridade, $12(48,0 \%)$ possuíam ensino médio completo. A renda domiciliar per capita variou de nenhuma renda até US\$1 111,11; 12 mulheres (48,0\%) tinham entre nenhuma renda e renda de US\$61,72. Quanto à moradia, 17 (68,0\%) residiam em áreas de periferia com condições precárias. Das 25 mulheres, 16 (64,0\%) apresentavam vínculo empregatício antes da gestação; e dessas 16 com vínculo, 12 $(75,0 \%)$ foram demitidas ou pediram demissão após o nascimento do bebê.

Conclusões. O perfil das mães revelou que a epidemia não foi equânime e atingiu preferencialmente mulheres de baixa renda e de estratos sociais desfavorecidos. Nesse sentido, acredita-se que a doença possa ser determinada pelas desigualdades sociais de saúde presentes no país. Os dados descritos podem fornecer subsídios para o planejamento de ações efetivas para garantir uma rede de proteção social para crianças com síndrome congênita do Zika e suas famílias.

Palavras-chave Vírus Zika; microcefalia; doenças transmissíveis; saúde pública; determinantes sociais da saúde; epidemiologia; Brasil.

O arbovírus foi isolado pela primeira vez ao final da década de 1940, em um macaco, em floresta da Uganda. O Zika vírus, cuja transmissão foi descrita em humanos apenas em 1952, teve sua circulação restrita ao continente Africano por cerca de 30 anos $(1$, 2). Entre 2014 e 2015, diversos municípios da região Nordeste do Brasil começaram a notificar a ocorrência de uma doença de sintomatologia leve, que causava prurido, manchas na pele, dor articular e febre. Seu desaparecimento ocorria depois de 4 a 5 dias, mesmo na ausência de tratamento; a doença não se enquadrava em nenhuma das hipóteses investigadas. Somente em 15 de maio de 2015 foi confirmada a autoctonia de Zika vírus no Brasil (3-5).

\footnotetext{
Universidade Federal do Espírito Santo (UFES), Programa de Pós-Graduação em Saúde Coletiva, Vitória (ES), Brasil. $\square$ Ethel Leonor Noia Maciel, ethel .maciel@gmail.com

2 Universidade Federal do Espírito Santo (UFES), Departamento de Ciências da Saúde, São Mateus (ES), Brasil.

3 Universidade Federal do Espírito Santo (UFES), Laboratório de Epidemiologia (LabEpi UFES), Vitória (ES), Brasil.
}

\footnotetext{
4 Pan American Health Organization (PAHO), Communicable Diseases and Environmental Determinants of Health Department, Washington (DC), Estados Unidos.

5 Faculdade de Direito de Vitória (FDV), Programa de Pós-Graduação em Direito, Vitória (ES), Brasil.
} 
Sequencialmente, registrou-se um expressivo aumento de internações de indivíduos com sintomas neurológicos nos hospitais de grande porte da Bahia, sendo comprovada a relação entre a infecção pelo Zika vírus e a síndrome de Guillain-Barré, a microcefalia e outras manifestações neurológicas (6). Além do forte impacto sofrido pelos estados da região Nordeste, a exposição ao vírus nos demais estados do país foi confirmada, tornando-se necessária a declaração de uma situação de emergência em saúde pública de importância nacional (ESPIN) e a notificação compulsória da doença (7).

A comunidade científica voltou-se para o Brasil e, após achados clínicos como microcefalia e diversas malformações fetais, detectadas especialmente no período pré-natal, descreveu o que a literatura chama hoje de síndrome congênita do Zika (SCZ). Essa nova síndrome reflete a dificuldade do Estado brasileiro de fornecer respostas para o controle do Aedes aegypti, vetor transmissor de muitas doenças, entre elas a Zika, que tem consequências nefastas para mulheres grávidas e seus bebês, decorrentes da SCZ $(8,9)$.

As questões de gênero também marcam o surto de Zika. Um estudo recente sugere que os impactos dessa epidemia sobre a vida sexual e reprodutiva das mulheres são preocupantes. A infecção pelo Zika vírus é um fardo para as mulheres, visto que muitas revelaram terem-se sentido culpabilizadas e pressionadas a não engravidar durante a epidemia (10). A maioria das que foram infectadas pelo Zika vírus na gestação eram pobres, nordestinas, pouco escolarizadas e com frágil inserção no mundo do trabalho; agora são, também, cuidadoras de crianças não protegidas pelo Estado (11).

De 2015 a janeiro de 2018, a Organização Pan-Americana da Saúde (OPAS) registrou 3720 casos confirmados de SCZ no território das Américas (12). Segundo o Ministério da Saúde, no período de novembro de 2015 a julho de 2018, foram notificados 16348 casos suspeitos de alterações no crescimento e desenvolvimento, possivelmente relacionados à infecção pelo Zika vírus. Desses, 3226 (19,7\%) foram confirmados. A maioria dos casos notificados concentra-se na região Nordeste $(59,3 \%)$, seguida pela região Sudeste $(24,7 \%)(13)$, da qual faz parte o estado do Espírito Santo. De novembro de 2015 a julho de 2018, foram registrados na região 406 casos suspeitos, dos quais 124 estão em investigação e 66 foram confirmados (13).

Conhecer o perfil das mães de crianças com a SCZ possibilita um melhor entendimento acerca dos padrões de ocorrência da doença e das lacunas na prevenção, e permite um melhor embasamento das estratégias para a assistência em saúde. Cabe ressaltar que não foram publicados até o presente momento estudos enfocando especificamente o perfil socioeconômico das mães e famílias diretamente afetadas pela SCZ. Em Pernambuco - local de início do surto e com maior número de bebês diagnosticados com SCZ no Brasil até 2018 - um levantamento revelou que mais da metade das famílias era de baixa renda. Das 209 mães de bebês com SCZ investigadas nesse levantamento, 77,0\% estavam abaixo da linha de pobreza e viviam em locais de condições precárias (14).

Nesse sentido, quanto mais informações e conhecimento são obtidos sobre determinada população, maiores são as chances de intervenções bem-sucedidas (15). Por isso, o presente estudo teve como objetivo descrever o perfil sociodemográfico de mães de crianças com SCZ confirmada pela Secretaria de Estado da Saúde do Espírito Santo no período de 2015 a 2016.

\section{MATERIAIS E MÉTODOS}

Trata-se de um estudo descritivo, transversal e de abordagem quantitativa, que faz parte de uma pesquisa mais ampla intitulada "As políticas públicas de saúde em situações de emergência: o surto do Zika vírus". O presente estudo contemplou todas as cidades do Espírito Santo nas quais residiam mães de bebês com SCZ. Além da descrição do perfil sociodemográfico, este estudo teve como um de seus objetivos a análise da percepção das mães sobre o diagnóstico, as condições de atendimento e o cotidiano de cuidados com a criança.

De acordo com o censo brasileiro, em 2010 o Espírito Santo tinha população de 3514952 habitantes, distribuídos de forma desigual entre 78 municípios: $83,40 \%$ da população residiam em área urbana e 16,60\% em área rural. O índice de desenvolvimento humano (IDH) no estado em 2010 era de 0,740, o sétimo no ranking nacional. Entretanto, o estado exibe desigualdades regionais relevantes, incompatíveis com o atual padrão de desenvolvimento econômico. Conta com uma rede de serviços de saúde que se concentra na capital e nos centros urbanos (16).

De acordo com o Comitê de Microcefalia da Secretaria de Estado da Saúde do Espírito Santo, desde o início do surto no estado, em 22 de novembro de 2015, até o dia 31 de dezembro de 2016, foram notificadas 264 gestantes suspeitas de SCZ. Desses casos, 49 recém-nascidos (RN) foram confirmados para SCZ, sendo que 10 foram abortos ou natimortos, permanecendo 39 RN confirmados para SCZ (17). Foram convidadas a participar da presente pesquisa todas as mães de bebês nascidos vivos entre os casos notificados em 2015 e 2016 com diagnóstico confirmado de SCZ pelo Comitê de Microcefalia da Secretaria de Estado da Saúde do Espírito Santo. Foram excluídas da amostra as 10 mulheres que tiveram abortos ou natimortos, por recomendação do Comitê de Ética em Pesquisa, considerando os objetivos gerais da pesquisa.

Das 39 mulheres elegíveis que foram convidadas a participar da pesquisa, houve uma perda amostral de 35,0\% em razão dos seguintes fatores: quatro mulheres mudaram de estado; duas mães eram menores de idade e não tiveram autorização dos pais para participar; uma mãe moradora de rua não foi encontrada; uma mãe entregou a criança para um abrigo, com destituição de pátrio poder sobre a mesma; duas mães que perderam seus bebês em 2017 por complicações do quadro da SCZ; uma mãe tinha seu bebê internado cronicamente e não apresentava condições emocionais de ser entrevistada; e três que não quiseram conceder entrevista. A coleta de dados foi realizada de maio a agosto de 2017, na casa das mães, em horário e data previamente agendados com as pesquisadoras, mediante a utilização de formulário para identificar o perfil sociodemográfico por meio das seguintes variáveis: idade, estado civil, número de filhos, número de pessoas na família, ocupação antes e após o nascimento do bebê, escolaridade, renda mensal individual, renda mensal familiar, cor de pele (autorreferida), número de cômodos na casa, acesso a algum benefício social e seguro de saúde, realização de pré-natal e número de consultas de pré-natal.

Calculou-se a renda domiciliar per capita, entendida como a divisão dos rendimentos domiciliares (incluindo pensões e benefícios sociais) pelo total de moradores (16). Os valores de renda apresentados foram estimados em dólar americano com equivalência para moeda brasileira, considerando a taxa de câmbio de US\$1,00 = R \$ 4,05 em 21 de setembro de 2018. Foi utilizado como método complementar de coleta de dados pelo 
pesquisador o diário de campo, para registro das observações inerentes ao local e às condições de moradia durante a visita às casas das mães.

Quanto à cor da pele, as categorias de autoidentificação do Instituto Brasileiro de Geografia e Estatística (IBGE), que realiza o censo, incluem: branca, preta, amarela e parda. Devido à miscigenação racial no Brasil, no presente estudo a categoria "não branca" aglutinou as cores preta e parda, levando em conta que ser "não branco" continua a ser um fator de menor mobilidade social ascendente e maior mobilidade descendente (18).

As informações obtidas pela aplicação do instrumento deram origem a um banco de dados que foi armazenado no software Microsoft Excel 2010 e serviram de base a este estudo para a realização das análises descritivas, feitas por meio de frequência absoluta e relativa, e apresentadas em formato de tabela.

O projeto de pesquisa foi aprovado pelo Comitê de Ética em Pesquisa do Centro de Ciências da Saúde da Universidade Federal do Espírito Santo (CEP/CCS/UFES, parecer 1.730.231 de 16/09/2016). Também foi aprovado pelo Comitê de Ética Internacional (PAHOERC) sob o parecer PAHO-2017-02-0013.

\section{RESULTADOS}

A idade das mulheres entrevistadas variou de 18 a 39 anos; $13(52,0 \%)$ tinham mais de 30 anos de idade e 16 (64,0\%) tinham companheiro. Quanto à escolaridade, 12 possuíam ensino médio completo $(48,0 \%$ ) (tabela 1 ). No que se refere à cor autorreferida, das 19 mulheres que se declararam não brancas (74,0\%), cinco $(20,0 \%)$ eram pretas e $14(56,0 \%)$ pardas.

Quanto à ocupação, nove $(36,0 \%)$ trabalhavam como donas de casa antes da gestação. As outras 16 (64,0\%) tinham diversas ocupações (administradora, ambulante, auxiliar odontológica, auxiliar de serviços gerais, atendente de telemarketing, balconista, garçonete, costureira, esteticista, empresária, operadora de caixa, vendedora, técnica de enfermagem, técnica em segurança do trabalho). Após a gestação e o nascimento do bebê com SCZ, das 16 mulheres que apresentavam vínculo empregatício antes da gestação, 12 (75,0\%) foram demitidas ou coagidas a pedirem demissão de seus empregos, segundo o relato das mesmas. O motivo principal do desligamento foi a dificuldade em conciliar o cuidado integral dos bebês doentes com a extensa jornada de trabalho fora de casa, além da necessidade contínua de faltar ao emprego para acompanhar os diversos atendimentos de saúde do filho com SCZ (tabela 1).

Quanto ao local de residência e às condições de moradia, das 25 mulheres, $18(72,0 \%)$ residiam na região metropolitana de Vitória e as demais residiam em cidades do interior. O diário de campo de pesquisa revelou que 17 (68,0\%) residiam em áreas de periferia desfavorecidas e com condições precárias (casas em encostas sem proteção e com risco iminente de desabamento, casas de madeira, casas de alvenaria sem pintura e acabamento, piso diretamente no chão de terra, bairros sem acesso a coleta de lixo e sem ligação de esgoto sanitário). Quanto à moradia, 17 $(68,0 \%)$ moravam de aluguel e $8(32,0 \%)$ possuíam casa própria.

No que diz respeito ao número de moradores por domicílio, houve variação de três a 12 pessoas. Em seis (24,0\%) domicílios, havia três moradores, em $10(40,0 \%)$ havia quatro moradores, em quatro $(16,0 \%)$ havia cinco moradores e em outros quatro $(16,0 \%)$ havia seis moradores. Um domicílio (4,0\%) tinha 12 moradores. Em relação à renda domiciliar per capita, houve variação de nenhuma renda até US\$ 1 111,11 (tabela 1).
TABELA 1. Características sociodemográficas das mães de crianças com síndrome congênita do vírus Zika, 2018

\begin{tabular}{|c|c|c|}
\hline Características sociodemográficas & No. & $\%^{\mathrm{a}}$ \\
\hline \multicolumn{3}{|l|}{ Idade (anos) } \\
\hline 18 a 24 & 6 & 24,0 \\
\hline 25 a 29 & 6 & 24,0 \\
\hline 30 a 34 & 4 & 16,0 \\
\hline 35 a 39 & 9 & 36,0 \\
\hline \multicolumn{3}{|l|}{ Cor da pele } \\
\hline Branca & 6 & 24,0 \\
\hline Não branca & 19 & 74,0 \\
\hline \multicolumn{3}{|l|}{ Escolaridade } \\
\hline Ensino fundamental incompleto & 4 & 16,0 \\
\hline Ensino fundamental completo & 1 & 4,0 \\
\hline Ensino médio incompleto & 4 & 16,0 \\
\hline Ensino médio completo & 12 & 48,0 \\
\hline Graduação & 1 & 4,0 \\
\hline Pós-graduação & 1 & 4,0 \\
\hline Não respondido & 2 & 8,0 \\
\hline \multicolumn{3}{|l|}{ Ocupação antes do nascimento do bebê } \\
\hline Do lar & 9 & 36,0 \\
\hline Trabalha fora (diversas profissões) & 16 & 64,0 \\
\hline \multicolumn{3}{|l|}{ Ocupação após nascimento do bebê } \\
\hline Do lar & 21 & 84,0 \\
\hline Trabalha fora (diversas profissões) & 4 & 16,0 \\
\hline \multicolumn{3}{|l|}{ Estado civil } \\
\hline Com companheiro & 16 & 64,0 \\
\hline Sem companheiro & 9 & 36,0 \\
\hline \multicolumn{3}{|l|}{ Número de filhos } \\
\hline 1 & 9 & 36,0 \\
\hline 2 a 3 & 9 & 36,0 \\
\hline 4 a 5 & 7 & 28,0 \\
\hline \multicolumn{3}{|l|}{ Renda per capita (US\$) ${ }^{b}$} \\
\hline Até 61,72 & 12 & 48,0 \\
\hline 61,97 a 123,45 & 8 & 32,0 \\
\hline 123,70 a 246,91 & 4 & 16,0 \\
\hline 247,16 a 1111,11 & 1 & 4,0 \\
\hline
\end{tabular}

Das participantes, $12(48,0 \%)$ recebiam o benefício de prestação continuada (BPC), conferido pelo sistema de assistência social brasileiro às famílias de pessoas com deficiência no valor de 1 salário mínimo mensal brasileiro (US\$ 235,55) (tabela 2). Para ter direito ao BPC, a família deve comprovar renda familiar per capita menor do que um quarto do salário mínimo vigente.

No que se refere aos serviços de saúde, 19 (76,0\%) não possuíam convênio privado de saúde. Somente uma (4,0\%) mulher não fez o pré-natal (tabela 2). Das que fizeram o pré-natal, 19 $(76,0 \%)$ foram atendidas no Sistema Único de Saúde (SUS) (tabela 2).

\section{DISCUSSÃO}

A epidemia de Zika que se iniciou no Nordeste brasileiro atingiu mulheres em idade reprodutiva, causando a SCZ. Foram mais afetadas as mães jovens, solteiras, com baixa escolaridade, 
TABELA 2. Acesso a políticas/serviços de saúde das mães de crianças com síndrome congênita do vírus Zika, 2018

$\begin{array}{lrr}\text { Acesso a políticas/serviços de saúde } & \text { No. } & \%^{\mathrm{a}} \\ \text { Benefícios governamentais } & 12 & 48,0 \\ \text { Sim } & 12 & 48,0 \\ \text { Não } & 1 & 4,0 \\ \quad \text { Não respondido } & & \\ \text { Plano de saúde } & 6 & 24,0 \\ \quad \text { Privado } & 19 & 76,0 \\ \text { Público } & & \\ \text { Pré-natal } & 24 & 96,0 \\ \text { Sim } & 1 & 4,0 \\ \quad \text { Não } & & \\ \text { Consulta pré-natal } & 1 & 4,0 \\ \quad \text { Nenhuma } & 3 & 12,0 \\ \text { 1 a } 5 & 18 & 72,0 \\ 6 \text { a 11 } & 3 & 12,0 \\ \text { Não respondido } & & \\ \text { Sistema de saúde utilizado } & 19 & 76,0 \\ \text { Público } & 3 & 12,0 \\ \text { Privado } & 3 & 12,0 \\ \text { Público e privado } & \end{array}$

pardas ou negras e pobres, que viviam em bairros mais desfavorecidos e com condições precárias de vida $(7,19)$. Esse perfil assemelha-se ao encontrado no presente estudo, exceto no que se refere à idade das mães, que tinham, na sua maioria, mais de 30 anos de idade.

Partindo do pressuposto de que o Brasil é um país de intensa desigualdade social, evidenciada por questões de raça/cor onde os não brancos têm renda, escolaridade e oportunidade de ascensão social menor quando comparados aos brancos (20) -, a predominância de não brancas afetadas pela SCZ sugere a pobreza como um determinante social na configuração da epidemia de Zika vírus no país.

As desigualdades sociais na saúde podem ser entendidas como a desigualdade social à luz da teoria da determinação social do processo saúde-doença. Isso significa que as diferenças no estado de saúde entre grupos podem ser definidas por características sociais, como renda, ocupação, raça e etnia, gênero e condições do local de moradia. Assim, a doença e sua distribuição populacional são produtos da organização social, em que a posição de classe e a reprodução social passam a ser vistas como determinantes do perfil da saúde e doença (21).

Quanto aos aspectos profissionais, observa-se no estudo o ônus do desemprego para as mães dos bebês com SCZ. Mesmo com o recebimento do $\mathrm{BPC}$, há que se considerar os custos com os tratamentos e cuidados dos bebês, que normalmente extrapolam o valor do benefício. Soma-se a isso a perda de renda dessas famílias com a saída da mulher do trabalho, visto que, geralmente, o cuidado com o bebê recai desproporcionalmente sobre as mulheres (22).

No que tange ao local e condições de moradia, a maioria vivia em regiões periféricas, em áreas desfavorecidas, com condições precárias de vida. Os resultados aqui relatados corroboram os achados de estudos recentes $(22,23)$, que concluíram que a maioria dos casos de SCZ ocorreu em famílias que vivem nas áreas mais marginalizadas das cidades e em áreas desfavorecidas.

Destaca-se que o fato de a maioria das mães morarem de aluguel, o que pode agravar a situação socioeconômica dessas famílias. A moradia é uma dimensão central para estudar as condições de vida da população. No Brasil, 7,9\% da população com renda per capita baixa (menor que 5,5 dólares/dia) tem ônus excessivo com aluguel (situação em que o aluguel do domicílio iguala ou supera $30 \%$ do rendimento domiciliar), sinalizando que os custos da moradia podem estar comprometendo outras necessidades (16).

No país, a definição do IBGE de renda menor que 5,5 dólares/dia define o limiar de pobreza. Cabe ressaltar que esse limiar é utilizado como condição para o recebimento do BPC rendimento domiciliar per capita abaixo de um quarto do salário mínimo vigente (US\$ 61,72) (16). Esta pesquisa encontrou renda familiar per capita predominante nessa faixa, o que, na prática, caracteriza as famílias estudadas na linha de pobreza. Um estudo realizado no estado de Sergipe encontrou famílias de crianças microcefálicas com renda familiar per capita média de US\$ 65,67 (24), revelando fragilidades socioeconômicas severas. Outro estudo realizado em Pernambuco encontrou renda per capita familiar média das crianças com SCZ de US\$ 98,76 (4).

Pesquisa recente apresentou menor taxa de prevalência de microcefalia em famílias nos estratos socioeconômicas mais ricos, demonstrando uma forte associação entre maior prevalência de microcefalia e nível socioeconômico baixo (23). No Brasil, a renda familiar per capita média da população no ano de 2016 foi de US\$ 302,71. No Espírito Santo, foi de US\$ 285,67. O estado do Maranhão teve a menor renda familiar per capita média, no valor de US\$141,97 (20). É importante destacar que $62 \%$ das mães deste estudo possuíam renda mensal domiciliar per capita menor que a média do estado do Maranhão.

O Brasil é um país de alta desigualdade de renda. O rendimento médio per capita de $20 \%$ dos domicílios com maiores rendimentos (US\$ 1 110,90) era 18,3 vezes maior que o rendimento médio dos $20 \%$ com menores rendimentos (US\$ 60,14) em 2016 (16). No que se refere ao BPC, sabe-se que o mesmo assume um importante papel na Política Nacional de Assistência Social e na redução da desigualdade social (25). Contudo, a maioria das famílias neste estudo que não recebia BPC por se enquadrar no critério de "excesso de renda" (renda per capita familiar superior a US\$ 61,72 ou um quarto do salário mínimo) se encontrava em condições precárias de vida. A norma de concessão do BPC determina que apenas pessoas de baixa renda e que vivenciam situações de extrema pobreza podem ter acesso ao benefício, o que exime o governo federal de assistir com políticas de transferência de renda famílias também pobres, mas não em extrema pobreza. O BPC é importante ferramenta para a reorganização da rotina das famílias de crianças com SCZ, principalmente aquelas nas quais crianças nasceram com microcefalia ou outras lesões incapacitantes graves relacionadas à infecção por Zika vírus na gestação (25).

Estimam-se em aproximadamente US\$ 1707,00 por mês os custos indiretos da SCZ que incidem principalmente sobre a família da criança (22). Esse valor é cerca de seis vezes o valor do benefício adicional do programa BPC fornecido a essas famílias. Outro estudo (26) estimou um custo total em torno de US\$ 3,8 milhões durante a vida para uma criança sobreviver com SCZ, com potencial de alcançar US\$ 10 milhões para aqueles que chegam à idade adulta. 
No que se refere aos serviços de saúde, a maioria das mães depende do sistema público de saúde e realizou o pré-natal no SUS. Isso demonstra a importância do acesso universal aos cuidados de saúde, garantidos pelo SUS para as famílias afetadas pela SCZ. Dado semelhante foi encontrado em Pernambuco, onde $97,0 \%$ das mães de crianças com SCZ utilizaram os serviços públicos de saúde na gestação e parto (27).

A maioria das mães fez o pré-natal e realizou de 6 a 11 consultas. Esse número está de acordo com a Política de Humanização do Parto Normal, que estabelece o número mínimo de consultas de pré-natal em seis, preferencialmente uma no primeiro trimestre, duas no segundo trimestre e três no último trimestre (28). Esse achado é corroborado por estudo realizado em Pernambuco (4), no qual todas as mães fizeram pelo menos uma consulta de pré-natal, sendo que a mediana de consultas foi igual a sete. Nesse sentido, a realização do pré-natal, bem como o número mínimo de consultas preconizado pelo protocolo do Ministério da Saúde (28), são fatores que desempenham papel fundamental em termos de prevenção e/ou detecção precoce de patologias, tanto maternas como fetais. No caso de gestantes com Zika, o pré-natal propicia à mãe informações sobre os riscos, acompanhamento das condições fetais e direcionamento do fluxo de atendimento e cuidados da criança ao nascer.

Ainda que acreditemos na importância de nossos achados para a saúde pública, consideramos relevante apresentar também as limitações deste estudo. Primeiro, algumas participantes foram excluídas da amostra por recomendação do Comitê de Ética. Também houve uma perda amostral, já descrita. Todavia, cabe ressaltar o alto grau de vulnerabilidade das mulheres no grupo da perda amostral, composto por adolescentes, moradora de rua e um caso de destituição de pátrio poder. A segunda limitação refere-se ao delineamento transversal do estudo, sem capacidade de identificar associações causais. Portanto, um nexo de causalidade entre a SCZ e os fatores sociodemográficos não pôde ser estabelecido.

Em conclusão, o perfil das mães de bebês com SCZ revelou que a epidemia não foi equânime no estado do Espírito Santo, atingindo preferencialmente mulheres de baixa renda e de estratos sociais menos favorecidos. Acredita-se que a SCZ possa ter determinação social arraigada nas desigualdades sociais de saúde presentes no país.
As desigualdades sociais em saúde são um desafio que precisa ser enfrentado por meio de políticas públicas eficientes, que permitam discutir todos os fatores que envolvem os determinantes sociais de saúde, com um olhar ampliado para o problema. Para tal, é preciso reconhecer o impacto das desigualdades e buscar compreender os processos que as produzem. Os executores das políticas públicas necessitam compreender que a renda per capita familiar não pode ser o único critério para concessão de benefício assistencial às famílias diretamente afetadas pela SCZ.

Acredita-se que os dados descritos neste estudo possam fornecer subsídios para elaborar ações efetivas que garantam uma rede de proteção social para crianças com SCZ e suas famílias. Por se tratar de um recente agravo à saúde, são necessários novos estudos, na modalidade caso-controle, para avaliar os determinantes sociais da SCZ e aferir associação entre eles.

Contribuição dos autores. ELNM, ECAB e PSSF conceberam e desenharam a pesquisa. GBS, HJSM, LCXL, TNP, CMMS, FP, realizaram a obtenção de dados e redigiram o artigo. Todos os autores analisaram e interpretaram os dados, revisaram criticamente o conteúdo e revisaram e aprovaram a versão final.

Agradecimentos. Este trabalho é parte do projeto "As políticas públicas em situações de emergência: análise do surto de Zika vírus", um produto da tese de doutorado de PSSF. Agradecemos às mulheres diretamente afetadas pelo surto por abrirem suas casas para os pesquisadores.

\section{Conflitos de interesse. Nada declarado pelos autores.}

Financiamento. Este estudo foi financiado pela Organização Pan-Americana da Saúde (OPAS) por meio do edital Programa conjunto HRP/TDR/OPS de Pequeñas subvenciones a la investigación sobre el brote del virus de Zika en las Américas.

Declaração. As opiniões expressas no manuscrito são de responsabilidade exclusiva dos autores e não refletem necessariamente a opinião ou política da RPSP/PAJPH ou da Organização Pan-Americana da Saúde (OPAS).

\section{REFERÊNCIAS}

1. Wikan N, Smith DR. Zika virus: history of a newly emerging arbovirus. Lancet Infect Dis. 2016;16(7):119-26.

2. Pinto Júnior VL, Luz K, Parreira R, Ferrinho P. Vírus Zika: revisão para clínicos. Acta Med Port. 2015;28(6):760-5.

3. Fantinato FFST, Araújo ELL, Ribeiro IG, Andrade MR, Dantas ALM, Rios JMT, et al. Descrição dos primeiros casos de febre pelo vírus Zika investigados em municípios da região Nordeste do Brasil, 2015. Epidemiol Serv Saude. 2016;25(4):683-90.

4. Vargas A, Saad E, Dimech GS, Santos RH, Sivini MAVC, Albuquerque LC, et al. Características dos primeiros casos de microcefalia possivelmente relacionados ao vírus Zika notificados na Região Metropolitana de Recife, Pernambuco. Epidemiol Serv Saude. 2016;25(4):691-700.

5. Vasconcelos PFC. Doença pelo vírus Zika: um novo problema emergente nas Américas? Rev Pan-Amaz Saude. 2015;6(2):9-10.

6. Malta JMAS, Vargas A, Leite PL, Percio J, Coelho GE, Ferraro AHA, et al. Síndrome de Guillain-Barré e outras manifestações neurológicas possivelmente relacionadas à infecção pelo vírus Zika em municípios da Bahia, 2015. Epidemiol Serv Saude. 2017;26(1):9-18.
7. Diniz D. Zika: from the Brazilian backlands to global threat. London: Zek Books; 2017.

8. Ventura CV, Maia M, Bravo-Filho V, Góis AL, Belfort JRR. Zika virus in Brazil and macular atrophy in a child with microcephaly. Lancet. 2016;387(10015):228.

9. Aragão MFV, Linden VVD, Brainer-Lima AM, Coeli RR, Rocha MA, Silva PS, et al. Clinical features and neuroimaging (CT and MRI) findings in presumed Zika virus related congenital infection and microcephaly: retrospective case series study. BMJ. 2016;353: i1901.

10. Linde AR, Siqueira CE. Women's lives in times of Zika: mosquito-controlled lives? Cad Saude Publica. 2018;34(5):e00178917.

11. Diniz D. Vírus Zika e mulheres. Cad Saude Publica. 2016;32(5): e00046316.

12. Pan American Health Organization (PAHO), World Health Organization (WHO). Zika suspected and confirmed cases reported by countries and territories in the Americas Cumulative cases, 20152017. Updated as of 4 January 2018. Washington: PAHO/WHO; 2017. Disponível em: https:/ / www.paho.org/hq/index.php?option 
$=$ com_content\&view $=$ article\&id=12390:zika-cumulative-cases \&Itemid=42090\&lang=en Acessado em dezembro de 2018.

13. Brasil, Ministério da Saúde, Secretaria de Vigilância em Saúde. Monitoramento integrado de alterações no crescimento e desenvolvimento relacionadas à infecção pelo vírus Zika e outras etiologias infecciosas, até a Semana Epidemiológica 30 de 2018. Boletim Epidemiológico. 2018;49(39):1-8. Disponível em: http://portalarquivos2 .saude.gov.br/images/pdf/2018/setembro/11/2018-047.pdf Acessado em dezembro de 2018.

14. Brasil, Ministério da Saúde, Secretaria de Atenção à Saúde. Protocolo de atenção à saúde e resposta à ocorrência de microcefalia relacionada à infecção pelo vírus Zika. Brasília: Ministério da Saúde; 2015. Disponível em: http://bvsms.saude.gov.br/bvs/publicacoes/pro tocolo_resposta_microcefalia_relacionada_infeccao_virus_zika.pdf Acessado em dezembro de 2018.

15. Luz EP, Dallepiane LB, Kirchner RM, Silva LAA, Silva FP, Kohler J, et al. Perfil sociodemográfico e de hábitos de vida da população idosa de um município da região norte do Rio Grande do Sul, Brasil. Rev Bras Geriatr Gerontol. 2014;17(2):303-14.

16. Instituto Brasileiro de Geografia e Estatística (IBGE). Síntese de indicadores sociais: uma análise das condições de vida da população brasileira. Rio de Janeiro: IBGE; 2016. Disponível em: https:/ / biblioteca.ibge.gov.br/visualizacao/livros/liv98965.pdf Acessado em dezembro de 2018.

17. Secretaria de Estado da Saúde do Espírito Santo. SESA divulga boletim de Zika e microcefalia. Espírito Santo: SESA; 2017. Disponível em: http:/ / saude.es.gov.br/Not\%C3\%ADcia/sesa-divulga-boletimde-zika-e-microcefalia-26 Acessado em 20 de fevereiro de 2018.

18. Instituto Brasileiro de Geografia e Estatística (IBGE). Características étnico-raciais da população: classificações e identidades. Rio de Janeiro: IBGE; 2013. Disponível em: https://biblioteca.ibge.gov.br /visualizacao/livros/liv63405.pdf Acessado em dezembro de 2018.

19. Butler D. Brazil asks whether Zika acts alone to cause birth defects. Nature. 2016;535(7613):475-6.

20. Instituto Brasileiro de Geografia e Estatística (IBGE). IBGE divulga o rendimento domiciliar per capita 2016. Rio de Janeiro: IBGE; 2016. Disponível em: ftp://ftp.ibge.gov.br/Trabalho_e_Rendimento/Pes quisa_Nacional_por_Amostra_de_Domicilios_continua/Renda _domiciliar_per_capita/Renda_domiciliar_per_capita_2016.pdf Acessado em 20 de fevereiro de 2018.

21. Barata RB. Como e por que as desigualdades sociais fazem mal à saúde. Rio de Janeiro: Editora FIOCRUZ; 2009. Disponível em: https://static.scielo.org/scielobooks/48z26/pdf/barata-97885754 13913.pdf Acessado em dezembro de 2018.

22. Programa das Nações Unidas para o Desenvolvimento (PNUD). Federação Internacional das Sociedades da Cruz Vermelha e do Crescente Vermelho. Uma avaliação do impacto socioeconômico do vírus Zika na América Latina e Caribe: Brasil, Colômbia e Suriname como estudos de caso. Nova York: PNUD; 2017. Disponível em: http://www.latinamerica.undp.org/content/dam/rblac/docs / Research\%20and\%20Publications/HIV/UNDP-RBLAC-Zika -07-20-2017-Portuguese-WEB.pdf Acessado em dezembro de 2018.

23. Souza WV, Albuquerque MFPM, Vazquez E, Bezerra LCA, Mendes ADCG, Lyra TM, et al. Microcephaly epidemic related to the Zika virus and living conditions in Recife, Northeast Brazil. BMC Public Health. 2018;18(1):130.

24. Cabral CM, Nóbrega MEB, Leite PL, Souza MSF, Teixeira DCP, Cavalcante TF, et al. Descrição clínico-epidemiológica dos nascidos vivos com microcefalia no estado de Sergipe, 2015. Epidemiol Serv Saude. 2017;26(2):245-54.

25. Pereira EL, Bezerra JC, Brant JL, Araújo WN, Santos LMP. Perfil da demanda e dos Benefícios de Prestação Continuada (BPC) concedidos a crianças com diagnóstico de microcefalia no Brasil. Cienc Saude Colet. 2017;22(11):3557-66.

26. Li R, Simmons KB, Bertolli J, Rivera-Garcia B, Cox S, Romero L, et al. Cost-effectiveness of Increasing access to contraception during the Zika virus outbreak, Puerto Rico, 2016. Emerg Infect Dis. 2017;23(1):74-82.

27. Costa AMA. A determinação social da microcefalia/Zika no Brasil. Waterlat-Gobacity Network. 2016;3(9):38-43.

28. Brasil, Ministério da Saúde, Instituto Sírio-Libanês de Ensino e Pesquisa. Protocolos da Atenção Básica: Saúde das Mulheres. Brasília: Ministério da Saúde; 2016. Disponível em: http://189.28.128.100 /dab/docs/portaldab/publicacoes/protocolo_saude_mulher.pdf Acessado em dezembro de 2018.

Manuscrito recebido em 19 de março de 2018. Aceito em versão revisada em 12 de novembro de 2018 .

\section{Congenital Zika syndrome: sociodemographic profile of mothers}

ABSTRACT Objective. Describe the sociodemographic profile of mothers of children with congenital Zika syndrome.

Method. This is a descriptive, cross-sectional, quantitative study. The 39 mothers of live born babies among the cases notified in 2015 and 2016 with confirmed diagnosis of congenital Zika syndrome in the state of Espírito Santo, Brazil, were invited to participate. Of these, 25 mothers were enrolled. Data were collected using a socioeconomic questionnaire and a field diary.

Results. Skin color was self-reported as non-white by $19 / 25$ mothers (74.0\%), and 16 (64.0\%) reported having a partner. Regarding schooling, $12(48.0 \%)$ had completed high school. Per capita income varied from no income to US\$1 111.11, and ranged from none to US\$ 61.72 for 12 women (48.0\%). Seventeen women (68.0\%) lived in underprivileged periphery areas with poor living conditions. Of the 25 women, 16 (64.0\%) had a job prior to the pregnancy; and of these, $12(75.0 \%)$ were fired or quit after the baby was born.

Conclusions. The profile of mothers shows that the Zika epidemics was not equanimous and preferentially affected women with low income and lower social class. In this sense, we believe that congenital Zika syndrome may be determined by social inequalities in Brazil. The data described in the present study may be useful for the planning of effective actions to ensure a social protection network for children with congenital Zika syndrome and their families. Brazil. 


\section{Síndrome congénito por el virus del Zika: perfil sociodemográfico de las madres}

RESUMEN Objetivo. Describir el perfil sociodemográfico de las madres de niños con síndrome congénito por el virus del Zika.

Métodos. Estudio descriptivo, transversal, de abordaje cuantitativo. Se invitó a participar en el estudio a 39 madres de niños nacidos vivos pertenecientes al grupo de casos notificados entre 2015 y 2016 con diagnóstico confirmado de síndrome congénito por el virus del Zika en el estado de Espírito Santo. De las 39 mujeres, 25 aceptaron participar. Para la recolección de datos se utilizó un formulario para identificar el perfil sociodemográfico y un diario de campo.

Resultados. De las 25 madres, 19 (74,0\%) manifestaron no ser blancas y $16(64,0 \%)$ tener una pareja. En cuanto a la escolaridad, 12 (48,0\%) poseían eduación media completa. El ingreso domiciliario per cápita varió desde ningún ingreso hasta US\$1 111,11; 12 mujeres (48,0\%) reportaron desde no tener ingresos hasta un ingreso de US\$61,72. En cuanto a la vivienda, 17 (68,0\%) vivían en zonas periféricas con condiciones precarias. De las 25 mujeres, 16 (64,0\%) presentaban vínculo laboral antes de la gestación, y de estas 12 (75,0\%) fueron despedidas o renunciaron después del nacimiento del niño.

Conclusiones. El perfil de las madres reveló que la epidemia no fue equitativa y alcanzó mayormente a mujeres de bajos ingresos y de estratos sociales desfavorecidos. En ese sentido, la enfermedad podría ser determinada por las desigualdades sociales de salud presentes en el país. Los datos encontrados son útiles para planificar acciones efectivas enfocadas a garantizar una red de protección social para niños con síndrome congénito por el virus del Zika y sus familias.

Palabras clave Virus Zika; microcefalia; enfermedades transmisibles; salud pública; determinantes sociales de la salud; epidemiología; Brasil. 